\title{
Surgical Removal of Traumatic Herniation of Buccal Fat Pad in Young Children
}

\author{
Agrawal NK, ${ }^{1}$ Dahal $S,{ }^{1}$ Khadka ${ }^{2}$
}

${ }^{1}$ Department of Dentistry

IOM, TUTH

Maharajgunj, Kathmandu

Nepal

${ }^{2}$ Department of Oral and Maxillofacial Surgery

UCMS-College of Dental Surgery

Ranigaon, Bhairahawa, Nepal

Corresponding Author

Nitin Kumar Agrawal

Department of Dentistry

IOM, TUTH

Maharajgunj, Kathmandu

Nepal

E-mail: cdrnitin@gmail.com

\section{Citation}

Agrawal NK, Dahal S, Khadka R. Surgical Removal of Traumatic Herniation of Buccal Fat Pad in Young Children. Kathmandu Univ Med J 2013;43(3):247-249.

\begin{abstract}
Intraoral herniation of the buccal fat pad is traumatic lesion of oral cavity occurring in young children. It frequently presents as an expanding pedunculated mass of soft tissue emanating from the buccal mucosa following a minor trauma to the buccal soft tissues. This article aims to report an interesting and rare lesion, wherein a tiny traumatic perforation of the buccal mucosa and buccinator muscle forced a large portion of the buccal fat pad to extrude into the oral cavity in a young boy. Such a situation can alarm any clinician and reinforces the importance of careful history taking and thorough examination, before treating patients.
\end{abstract}

\section{KEY WORDS}

Buccal fat, herniation, suctorial pad, surgical removal, trauma

\section{INTRODUCTION}

The buccal fat represents a specialized type of tissue that is distinct from subcutaneous fat which serves to line the masticatory space, separating the muscles of mastication from each other, from the zygomatic arch, and from the ramus of the mandible.

The buccal fat consists of a central body and four extensions; buccal, pterygoid, superficial, and deep temporal. The main body is situated deep along the posterior maxilla and upper fibers of the buccinator. The buccal extension is located superficially within the cheek, while the pterygoid and temporal extensions are more deeply situated. The buccal extension is encapsulated by a parotidomassetric fascia and enters the cheek below the parotid duct. It extends along the anterior border of the masseter and descends into the mandibular retromolar region. ${ }^{1,2}$
The buccal fat pad has increased volume in neonates and infants and has been referred to as the "suctorial pad." 3,4 The suckling activity in infants and young children may actually promote herniation following an injury to the buccal tissues. However traumatic herniation of the buccal fat pad usually presents immediately, or within several hours of the initial injury. The purpose of this article is to report a case of traumatic herniation of buccal fat pad in a young boy. ${ }^{5}$

\section{CASE REPORT}

A 2 years and 10 months old male patient reported to the department for evaluation of oral mass. He had fallen with toothbrush in his mouth, about six hours back. The toothbrush was intact and did not break. Father reported 
bleeding from right buccal mucosa, and there was no mass protruding in the oral cavity at the time of injury. Later on they noted a large mass extending from the right buccal mucosa.

Intra oral examination revealed a reddish, soft-pedunculated mass, projecting from the right buccal mucosa (Fig. 1). The mass was non tender and was protruding in between the

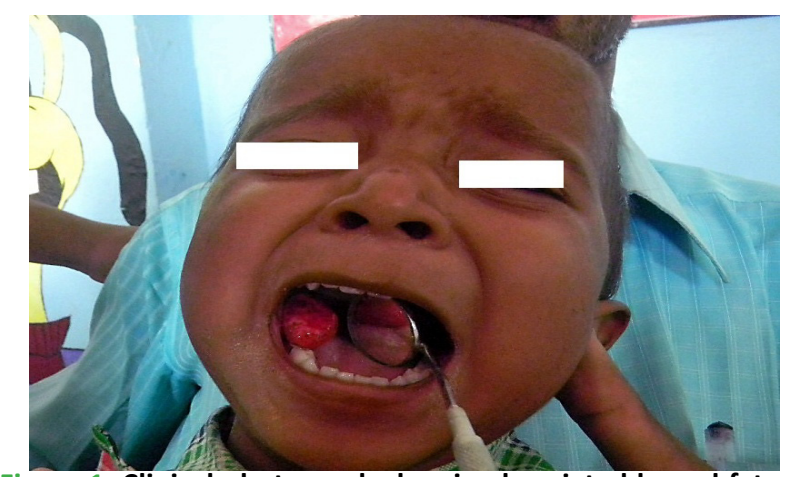

Figure 1. Clinical photograph showing herniated buccal fat pad from right buccal mucosa.

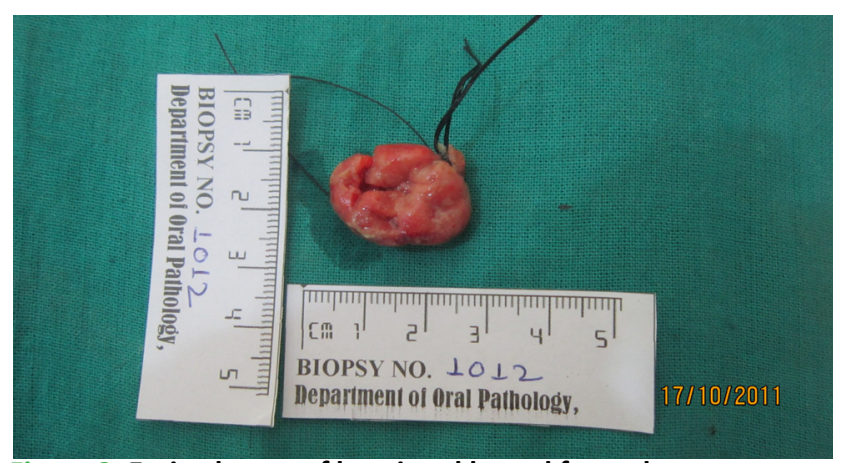

Figure 2. Excised mass of herniated buccal fat pad.

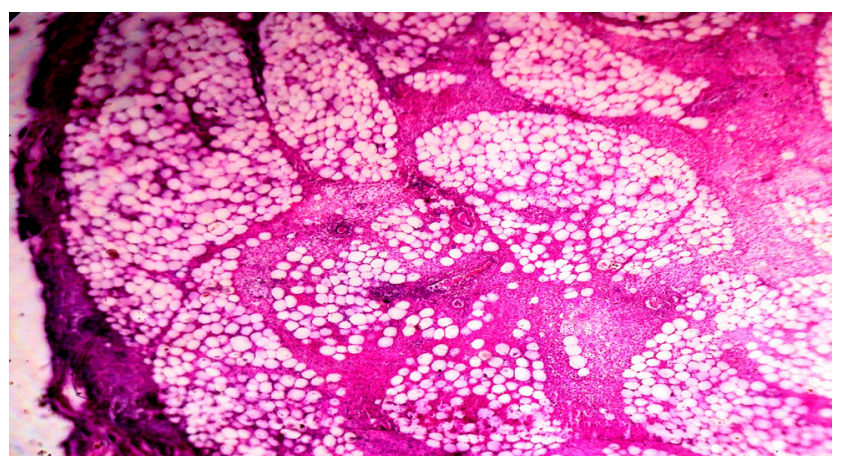

Figure 3. Photomicrograph showing well-circumscribed lobules of mature fat cells separated by thin fibrous septa (H\&E, original magnification * 40).

occlusal surfaces of maxillary and mandibular posterior teeth. Hence, patient was unable to close his mouth and was unable to eat since morning. The clinical diagnosis made was herniation of the buccal fat pad. The patient was placed under antibiotic coverage and was advised soft diet. Routine blood examination was performed and the patient was recalled the next day. Under local anaesthesia, a suture was tied around the peduncle and the base of the mass was easily excised with minimal bleeding. 4-0 resorbable suture was placed to close the wound primarily. The patient was examined after five days and the postoperative course was uneventful.
The excised mass measured $2.3 \mathrm{~cm} * 1.7 \mathrm{~cm} * 1 \mathrm{~cm}$, was lobulated and firm in consistency (Fig. 2). The mass floated when placed in $10 \%$ formalin, indicating the presence of adipose tissue. On microscopic examination, wellcircumscribed lobules of mature fat cells separated by thin fibrous septa could be seen (Fig. 3). Hence, final diagnosis was herniation of buccal fat pad.

\section{DISCUSSION}

The buccal fat pad was first described in 1732 by Heister as "glandular morlares who defined it as glandular structure. ${ }^{6}$ Bichat in 1802 named it as "buccal fat pad of Bichat" or the "corpus adeposum buccae" due to its fatty nature. However Stuzin described it as a rounded, biconvex structure with a thin but distinctive capsule lying between the buccinator and masseter muscles. ${ }^{1,5}$

Clinically, the buccal fat pad can be used for both reconstructive and cosmetic surgery. ${ }^{8}$ A review detailed the clinical/ surgical anatomy pertinent to plastic surgery. ${ }^{9}$ Both free and pedicle grafts have been described. ${ }^{10-12}$ For pedicle grafts, the blood supply of the buccal fat pad has been identified as arising from buccal and deep temporal branches of the maxillary artery as well as the transverse facial branch of the superficial temporal artery. ${ }^{12}$

Trauma affects buccal pad of fat more frequently in infants and young children resulting in traumatic herniation of the buccal fat pad. This may include fall with a sharp object in the mouth, or a fall resulting in a laceration of the buccal tissues from occlusal trauma

Herniation of the buccal fat pad means intraoral herniation of the buccal fat pad. It is soft, nontender, nonpulsatile, and does not blanch. It is pedunculated in nature and originates from the buccal mucosa near the parotid duct at the level of the maxillary occlusal plane. The mass is typically about $3 \mathrm{~cm} \times 1.5 \mathrm{~cm} \times 1.5 \mathrm{~cm}$ in dimension. On the other hand, in case of the outward prolapse of the lower portions of buccal fat pad, resulting in facial mass, it has been mentioned as pseudoherniation of the buccal fat pad, or "chipmunk cheek." 2,13

The first case of traumatic herniation of the buccal fat pad was first reported by Clawson et al in 1968, and then Brooke et al reported another case and coined the term traumatic pseudolipoma. ${ }^{14,15}$ Data indicates this event typically occurs in children ranging from four months to four years; Median age of reported cases is 20 months. ${ }^{5}$

There are two probable factors in the exclusive occurrence of the lesion in children. Firstly, the buccal fat pad is particularly prominent in neonates and infants, and has an increased risk of herniation. Secondly, children frequently hold foreign objects in their mouths and subsequently are prone to be traumatized by them. ${ }^{2,16}$ As to the anatomic location of this lesion, Matarasso suggested that a defect or weakness in the parotidomasseteric fascia of the region contributed to the occurrence. ${ }^{13}$ 
The clinical differential diagnosis includes pyogenic graunloma, inflammatory pseudotumor, foreign body graunloma, traumatic neuroma, lipoma, hemangioma, and salivary neoplasm. Generally a history of trauma, an absence of mass prior to the accident, its occurrence in infants and children, the specific anatomic site, adipose appearance and the histopathology serves to diagnose the condition. ${ }^{2,17}$

Histologically a connective tissue stroma with sheets and groups of adipocytes without atypia and no epithelial cover, with a varying degree of inflammatory cell infiltration is seen. Necrotic change with bacterial proliferation may be seen on the surface. ${ }^{3,18}$

There are two modalities of treatment for the traumatic herniation of the buccal fat pad. When the case is reported

\section{REFERENCES}

1. Stuzin JM, Wagstrom L, Kawamoto HK, Baker TJ, Wolfe A. The anatomy and clinical applications of the buccal fat pad. Plast Reconstr Surg. 1990;85:29-37.

2. Horie $n$, Shimoyama $T$, Kaneko $T$, Ide Fumio. Traumatic herniation of the buccal fat pad. Ped Dent. 2001;23(3):249-252.

3. Messenger K. L, Cloyd W. Traumatic herniation of the buccal fat pad, Report of a case. Oral Surg. 1977; 43:41-43.

4. Wolford D. G. Stapleford R. G. Forte R.A. Heath M. Traumatic herniation of the buccal fat pad. J Am Dent Assoc. 1981;103: 593-594.

5. Carter TG, Egbert M. Traumatic prolapsed of the buccal fat pad (Traumatic Pseudolipoma): A case report and literature review. J Oral Maxillofac Surg 2005;63:1029-1032.

6. Heister L: Compendium Anatomicum, Norimbergae, 1732.

7. Bichat F. Anatomie generale, appliqué a la physilogie et a la medicine. Paris, Grosson, Gabon et cie, 1802.

8. Hines N, Lantos G. Herniation of buccal fat pad into the maxillary antrum: CT findings in three cases. Am J Neuroradiol 2006;27:936937.

9. Zhang HM, Yan YP, Qi KM. Anatomical structure of the buccal fat pad and its clinical adaptations. Plast Reconstr Surg. 2002;109:2509-18.

10. Neder A. Use of buccal fat pad for grafts. Oral Surg Oral Med Oral Pathol. 1983;55:349-50. immediately, preferably within four hours, and the protruded mass is small with minimal inflammatory change, the lesion is able to be repositioned immediately. ${ }^{16,19}$ If the mass is too large to replace in the limited laceration injury site or necrosis has appeared, it is recommended to surgically remove the mass from the base. Important thing to consider in either of cases is not to traumatize the adjacent parotid papilla and duct. ${ }^{2}$ In our case, patient had reported late and the size was relatively large, hence, the mass was excised. There have been no reported cases of recurrence. ${ }^{2-5,13-19}$

Appearance of this lesion may seem to be an alarming situation for any health care professional. A sound knowledge of specific site of occurrence of this lesion can help a professional in diagnosing and managing this lesion promptly.

11. Egyedi P. Utilization of the buccal fat pad for closure of oro-antral and/ or oro-nasal communications. J Maxillofac Surg. 1977;5:241-44.

12. Tideman $H$, Bosanquet $A$, Scott J. Use of the buccal fat pad as a pedicled graft. J Oral Maxillofac Surg. 1986;44:435-40.

13. Matarasso A. Pseudoherniation of the buccal fat pad: a new clinical syndrome. Plast Reconstr Surg. 1997; 100:723-730.

14. Clawson JR, Kline KK, Armbrecht EC: Trauma-induced avulsion of the buccal fat pad into the mouth: Report of case. J Oral Surg. 1968;26:546.

15. Brooke RI, MacGregor AJ. Traumatic pseudolipoma of the buccal mucosa. Oral Surg Oral Med Oral Pathol. 1969;28:223.

16. Fleming $P$. Traumatic herniation of buccal fat pad: a report of two cases. Br J Oral Maxillofac Surg. 1986;24:265-268.

17. Patil R, Singh S, Reddy VVS. Herniation of the buccal fat pad into the oral cavity;A case report. J Indian Soc Pedod Prev Dent. 2003;21(4):152-154.

18. Haria S, Kidner G, Shepherd JP. Traumatic herniation of the buccal fat pad into the oral cavity. Int J Paediat Dent. 1991; 1:159-162.

19. Muroki, T, Nakagawa K, Narinobou M, Yamamoto E. A case of traumatic herniation of buccal fat pad: report of a case. J Jpn Stomatol Soc. $1996 ; 45: 46-50$. 